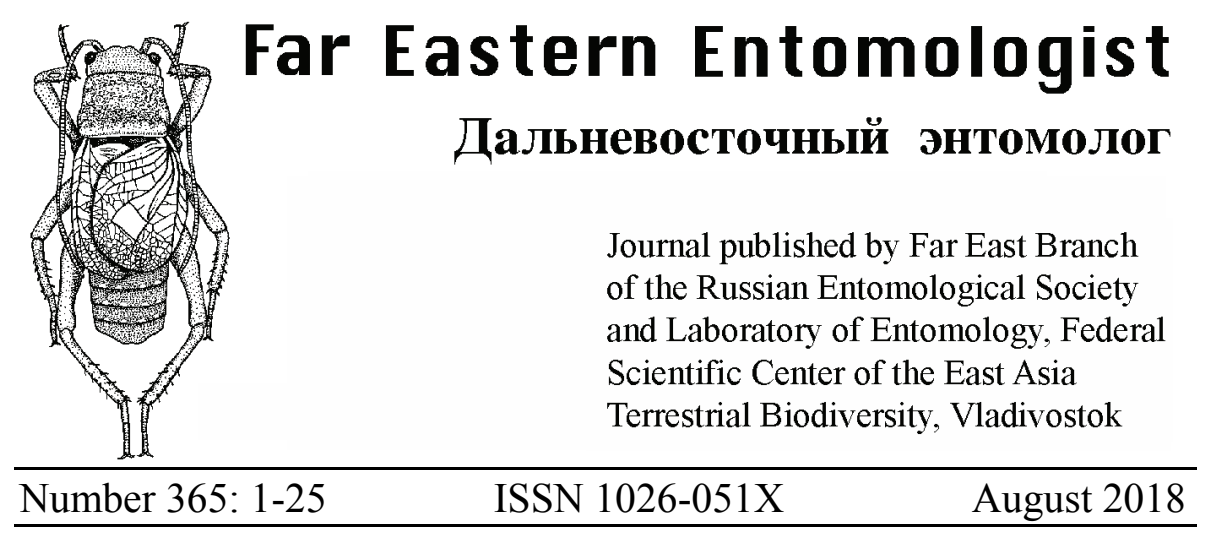

https://doi.org/10.25221/fee.365.1

http/urn:Isid:zoobank.org:pub:02387D27-9229-448B-9727-2C240AB4F04E

\title{
A NEW SUBFAMILY OF DOLICHOPODIDAE (DIPTERA) FOR TENUOPUS CURRAN, 1924 WITH DESCRIPTION OF NEW SPECIES FROM TROPICAL AFRICA
}

\author{
I. Ya. Grichanov \\ All-Russian Institute of Plant Protection, Podbelskogo 3, St. Petersburg-Pushkin,
} 189620, Russia.E-mail: grichanov@mail.ru

Summary. A new subfamily Tenuopodinae Grichanov, subfam. n. is created for the genus Tenuopus Curran, 1924, sharing some features of Neurigoninae, Peloropeodinae and Sciapodinae. Tenuopus bururiensis sp. n. and T. kirkspriggsi sp. n. from Burundi, T. gorongosaensis sp. n. from Mozambique, T. kylei sp. n. and $T$. soderlundi sp. n. from South Africa, and T. lomholdti sp. n. from Tanzania are described. Neotype of T. unicolor (Becker, 1914) is here designated and described. Description of unknown male of T. shcherbakovi Grichanov, 1996 is given. A revised key to species of Tenuopus is also provided and new records for known African species are given.

Key words: Diptera, Dolichopodidae, taxonomy, new subfamily, Tenuopus, new species, key, new records, Tropical Africa.

И. Я. Гричанов. Новое подсемейство для рода Tenuopus Curran, 1924 (Diptera: Dolichopodidae) с описанием новых видов из тропической Африки // Дальневосточный энтомолог. 2018. N 365. C. 1-25.

Резюме. Для рода Tenuopus Curran, 1924 установлено новое подсемейство Tenuopodinae Grichanov, subfam. n., сочетающее некоторые признаки Neurigoninae, Peloropeodinae и Sciapodinae. Описаны пять новых для науки видов: 
Tenuоpus bururiensis sp. n. и T. kirkspriggsi sp. n. из Бурунди, T. gorongosaensis sp. n. из Мозамбика, T. kylei sp. n. и T. soderlundi sp. n. из Южной Африки, $T$. lomholdti sp. n. из Танзании. Обозначен неотип T. unicolor (Becker, 1914) и приведено его описание. Описан ранее неизвестный самец $T$. shcherbakovi Grichanov, 1996. Составлена новая определительная таблица видов рода Tenuорus и приведены новые находки для известных африканских видов.

\section{INTRODUCTION}

The genus Tenuopus was established by Curran (1924) for a new species Saucropus univittatus Curran nec Loew, 1858 (misidentification) from South Africa. In subsequent publications Curran described T. acrosticalis Curran, 1927 and T. frontalis Curran, 1927 (female) and transferred Saucropus cyanescens Loew, 1858 in the genus Tenuopus, relating it with the subfamily Chrysosomatinae (Curran 1927a, 1927b), now synonym of Sciapodinae. Later Parent (1931, 1934, 1939) renamed T. univittatus (Curran), described three new species and excluded Saucropus univittatus and S. cyanescens from the genus. Dyte \& Smith (1980) transferred Psilopus unicolor Becker, 1914 to the genus Tenuopus, listing the latter within the subfamily Neurigoninae. All species are known from South and Tropical Africa, though an undescribed species was mentioned by Dyte (1975) from the Oriental Region. Grichanov $(1996,2000)$ has described six new species of the genus: Tenuopus fursovi Grichanov, 1996, T. kononenkoi Grichanov, 1996, T. ntchisi Grichanov, 2000, T. shcherbakovi Grichanov, 1996, T. taitensis Grichanov, 2000 and T. zverevi Grichanov, 1996. Later new records and new illustrations for some species have been published (Grichanov, 2011; Grichanov et al., 2011a, b). The genus has been catalogued by Grichanov (2018). Its position has been recently doubted (Naglis, 2001; Grichanov \& Brooks, 2017). Convex mesonotum and preapical femoral setae do not agree with a concept of the subfamily Neurigoninae diagnosed by Bickel (1998), Naglis (2001) and Grichanov \& Brooks (2017).

\section{MATERIALS AND METHODS}

Material cited in this work is housed at the National Museum, Bloemfontein, South Africa (BMSA), the Natural History Museum of Denmark, Zoological Museum, University of Copenhagen (ZMUC), the Natal Museum, Pietermaritzburg, KwaZulu Natal, South Africa (NMSA), the Museum of Zoology, University of Lund, Sweden (MZLU) and the Zoological Museum of Moscow State University, Moscow, Russia (ZMUM). Specimens have been studied and photographed with a ZEISS Discovery V-12 stereo microscope and an AxioCam MRc5 camera. Genitalia preparations have been photographed with a ZEISS Axiostar stereo microscope and an AxioCam ICc3 camera. Morphological terminology and abbreviations follow Cumming \& Wood (2017) and Grichanov \& Brooks (2017). The relative lengths of the antennomeres and podomeres should be regarded as representative ratios and not measurements. Body length is measured from the base 
of the antenna to the tip of abdominal segment 6 . Wing length is measured from the base to the wing apex. The figures showing the hypopygium in lateral view are oriented as it appears in the intact specimens, with the morphologically ventral surface of the genitalia facing upwards, dorsal surface downwards, anterior end facing left and posterior end facing right.

\section{TAXONOMY}

\section{Subfamily Tenuopodinae Grichanov, subfam. $n$.}

Type genus: Tenuopus Curran, 1924, here designated.

DIAGNOSIS. Single genus Tenuоpus comprising 19 Afrotropical species. All the species examined and described have the following features. Long (5 to $10 \mathrm{~mm}$ ), mostly yellow body; head with the strongly excavated vertex on either side of the ocellar tubercle; one pair of ocellar, occipital and postvertical bristles; vertical setae absent; proboscis with a pair of black lateral setae and yellow hairs; scape bare, pedicel with digitiform inner projection upon postpedicel, more developed in males; arista-like stylus dorsal, short pubescent. Mesonotum convex, no mesoscutal flattening; six or seven dorsocentral bristles with first bristle somewhat smaller; scutellum with two strong bristles. Legs mostly yellow, coxae with yellow hairs and black bristles, hind coxa with one external bristle; mid and hind femora usually with one preapical seta. Wing vein $\mathrm{R}_{2+3}$ reaches costa in apical fifth of wing, being nearly parallel with $\mathrm{R}_{4+5} ; \mathrm{M}_{1}$ with gentle arc to apex, reaching costa before wing apex, near $\mathrm{R}_{4+5} ; \mathrm{M}_{2}$ usually present as fold on membrane; $d m-m$ straight, $b m-m$ reduced. Abdomen of six segments with strong marginal bristles, without tergal window in segment 1, and with less sclerotised "pseudotergite" between segments 1 and 2 (see Parent, 1938; Bickel, 1994); seventh segment and hypopygium small, epandrium partly concealed; cercus usually short and simple, surstylus usually long, often bifurcated; at least one very long and a few short epandrial lobes.

NOTES. The general habitus and male terminalia of Tenuopus suggest its placement in the Neurigoninae, and the genus has historically been assigned to the latter subfamily, but unlike neurigonines, species of Тепиориs have the thorax with the posterior mesonotum convex and the mid and hind femora usually each with anterior preapical seta (similar to Peloropeodinae). Peloropeodine genera includes rather small representatives ( 1 to $3 \mathrm{~mm}$ ) with posterior mesonotum distinctly flattened and slightly depressed, wing veins $\mathrm{R}_{4+5}$ and $\mathrm{M}_{1}$ subparallel, and $\mathrm{M}_{1}$ nearly straight (e.g., Bickel, 2009; Grichanov \& Brooks, 2017), strongly differing from both Tenuоpus and Neurigoninae by these and other features. Tenuopus and most Sciapodinae share such characters as vertex of head strongly excavated on either side of ocellar tubercle, wing vein $\mathrm{M}_{1+2}$ distinctly branched, with vein $\mathrm{M}_{2}$ present at least as a fold in membrane (vein $\mathrm{M}_{2}$ absent in species of the sciapodine tribe Mesorhagini); thorax with mesonotum usually short, about as wide as long; posterior mesonotum not flattened. Grichanov \& Brooks (2017) considered Tenuopus as a 
genus incertae sedis, distinguishing it from Sciapodinae by the following combination of characters: head without vertical setae in both sexes; antennal pedicel forming short thumb-like projection on inner side of postpedicel; abdominal segment 1 without tergal window; male terminalia with hypopygium mostly exerted, but with small segment 7; hypandrium strongly reduced. In this paper I consider the listed diagnostic characters of Tenuopus as having importance at the family level, being significant for the establishment of a new subfamily Tenuopodinae, even more significant than characters used recently for substantiation of some new dolichopodid subfamilies (e.g., Yang et al., 2006).

\section{Genus Tenuopus Curran, 1924}

Tenuopus Curran, 1924: 228.

Type species: Saucropus univittatus Loew, 1858 [sensu Curran, misidentification] = Tenuopus erroneus Parent, 1934, by original designation.

\section{Key to species}

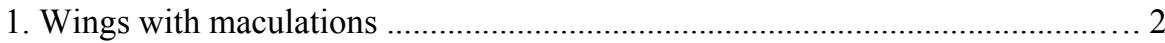

- Wings monochrome or hyaline ..................................................................... 3

2. Wing with one apical spot along costa ............................. T. maculatus Parent

- Wing with three rounded spots in apical half, in females somewhat diffused

3. Males

- Females ............................................................................................... 19

4. Acrostichals usually weak, in a single row ...................................................... 5

- Acrostichals usually strong, arranged in two rows extending to posterior third of mesonotum ............................................................................................. 9

5. Acrostichals strong, extending to posterior third of mesonotum; $3^{\text {rd }}-5^{\text {th }}$ segments of fore tarsus with posterior and posteroventral rows of strong setulae ............ 6

- Acrostichals weak and restricted to anteriormost of mesonotum, or absent; at least $3^{\text {rd }}$ segment of fore tarsus without strong setulae

6. Postpedicel oval, longer than high; cercus band-like, almost evenly wide

T. unicolor Becker

- Postpedicel subtriangular, as long as high; cercus broadest in basal half T. shcherbakovi Grichanov

7. $4-5^{\text {th }}$ segments of fore tarsus with short lateral black plumage

T. erroneus Parent

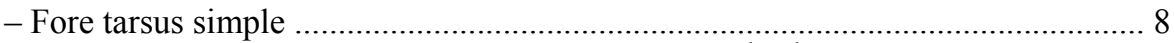

8. $\mathrm{M}_{4} 3$ times longer than $d m-m$; abdomen with $2^{\text {nd }}-4^{\text {th }}$ segments mostly yelloworange, each with broad black posterior triangular spot ........ T. cognatus Parent

$-\mathrm{M}_{4}$ at least 4 times longer than $d m-m$; abdomen with $2^{\text {nd }}-4^{\text {th }}$ segments entirely yellow T. soderlundi $\mathbf{s p .} \mathbf{n}$. 
9. Mid femur with 6-8 long black ventral bristles in middle half, longer than diameter of femur, and with some white hairs; fore basitarsus 1.5 times as long as fore tibia, with 4 dorsal setae

T. zverevi Grichanov

- Mid femur with hairs only, fore basitarsus various in length, with no more than 2 dorsal setae 10

10. Mid and hind femora with black ciliation or glabrous ventrally; fore basitarsus with no more than 1 dorsal seta

- Mid and hind femora with white hairs beneath, fore basitarsus with 2 dorsal setae 17

11. Fore basitarsus with 1 dorsal seta, sometimes small; other tarsomeres without strong setulae or long hairs

- Fore basitarsus without setae; $3^{\text {rd }}-5^{\text {th }}$ segments of fore tarsus with posterior and posteroventral rows of strong setulae or long hairs

12. Fore basitarsus about as long as fore tibia; surstylus deeply bifurcated, with thin and long lobes

T. kononenkoi Grichanov

- Fore basitarsus about 1.3 times as long as fore tibia; surstylus bifurcated at apex, with broad lobes T. kylei sp. n.

13. Fore tibia 1.5 times longer than fore basitarsus; $4^{\text {th }}$ segment of fore tarsus longer than $3^{\text {rd }}$ segment 14

- Fore tibia at most 1.25 times longer than fore basitarsus; $4^{\text {th }}$ segment of fore tarsus shorter than $3^{\text {rd }}$ segment

14. Cercus rounded, with long narrow setosed basoventral process; surstylus about twice larger than cercus T. taitensis Grichanov

- Cercus subtriangular, without process; surstylus about as large as cercus ...

T. lomholdti sp. $\mathbf{n}$.

15. $2^{\text {nd }}$ segment of fore tarsus bearing short anterior comb of hairs, as long as diameter of tarsomere, elongate posterior and posteroventral setulae; $3^{\text {rd }}-5^{\text {th }}$ segments ventrally bare, slightly swollen at apex; $4-5^{\text {th }}$ segments with $1-2$ long apicodorsal hairs ................................................................... T. ntchisi Grichanov

$-2^{\text {nd }}$ segment of fore tarsus without anterior comb of hairs; $3^{\text {rd }}-5^{\text {th }}$ segments ventrally bare, slightly swollen at apex; $4-5^{\text {th }}$ segments without long apicodorsal hairs ...

6. Fore tibia without elongate hairs; cercus less than half as long as epandrium, simple, subtriangular T. gorongosaensis sp. n.

- Fore tibia with elongate ventral hairs; cercus as long as epandrium, simple, swollen at base, narrow at apex

T. kirkspriggsi $\mathbf{s p .} \mathbf{n}$.

17. All the surface between dorsocentrals black-green; surstylus deeply bifurcated T. acrosticalis Curran

- Median green-brownish stripe of mesonotum half as wide as surface between dorsocentral bristles; surstylus not bifurcated

18. Fore tarsus with $2^{\text {nd }}$ segment bearing small basoventral cicatrix; surstylus narrow

- Fore tarsus with $2^{\text {nd }}$ segment simple; surstylus broad T. fursovi Grichanov

19. Acrostichals in a single row or absent T. bururiensis, sp. n.

- Acrostichals in two rows, sometimes irregular.... 20 
20. Acrostichals strong, extending to posterior third of mesonotum; frons black, pollinose

- Acrostichals weak and restricted to anteriormost of mesonotum, or absent; frons shining blue .. 22

21. Postpedicel oval, with rounded apex

- Postpedicel subtriangular, with sharp or right-angular apex

T. shcherbakovi Grichanov

22. Hind tarsus entirely black; $R_{4+5}$ and $M_{1}$ reaching costa at wing apex T. cognatus Parent

- Hind tarsus yellow at base; $\mathrm{M}_{1}$ reaching costa before wing apex

T. erroneus Parent

23. Fore tibia with 2 basal dorsal setae only, fore basitarsus without dorsal setae ... 24

- Fore tibia with 2 basal dorsal and 2 dorsal setae in middle; fore basitarsus with 1-2 dorsal setae; acrostichals arranged in two regular rows ....

26

24. Acrostichals weak, arranged in two irregular rows; $\mathrm{M}_{4}$ no more than 2.5 times longer than $d m-m$

T. kononenkoi Grichanov

- Acrostichals arranged in two regular rows; $\mathrm{M}_{4}$ more than 3 times longer than $\mathrm{dm}$ $m$.....

T. taitensis Grichanov

25. Hind tibia mostly brown; hind tarsus entirely black

- Hind tibia and basal half of hind basitarsus yellow T. gorongosaensis sp. $\mathbf{n}$.

26. Frons entirely pollinose, fore basitarsus 1.2 times longer than fore tibia

T. acrosticalis Curran

- Frons more than half shining green; fore basitarsus as long as fore tibia T. frontalis Curran

\section{Descriptions and new records}

Tenuopus bururiensis Grichanov, sp. $\mathbf{n}$. Figs $1,8,15$

TYPE MATERIAL. Holotype - $\widehat{\jmath}$, Burundi: Bururi Prov., Res. Nat. Forestière de Kigwena, $4^{\circ} 05.949^{\prime} \mathrm{S}, 2^{\circ} 30.455^{\prime} \mathrm{E}, 810 \mathrm{~m}, 17-20 . \mathrm{XI}$ 2010, A.H. Kirk-Spriggs $/$ malaise trap, circumguinean forest [BMSA].

DESCRIPTION. Male. Head: frons black, whitish pollinose; one pair of short postvertical setae, as long as uppermost postocular seta; upper postocular setae black, increasing in length upward; lateral and lower postoculars white; ventral postcranium covered with irregular white hairs; face silvery-white, 8 times as high as wide in middle, nearly as wide as postpedicel; clypeus slightly bulging; antennae as long as height of head, with yellow scape and pedicel and yellow-orange postpedicel; pedicel projected distally on inner side, with a crown of short black setae, one of dorsal setae as long as pedicel; postpedicel rounded, slightly longer than high at base (2.1/1.7); arista-like stylus dorsal, with short hairs; length ratio of scape to pedicel to postpedicel to stylus ( $1^{\text {st }}$ and $2^{\text {nd }}$ segments), 5/5/7/2/26; palpus and proboscis short, yellow, covered with white hairs, proboscis also with a pair of black lateral setae. 


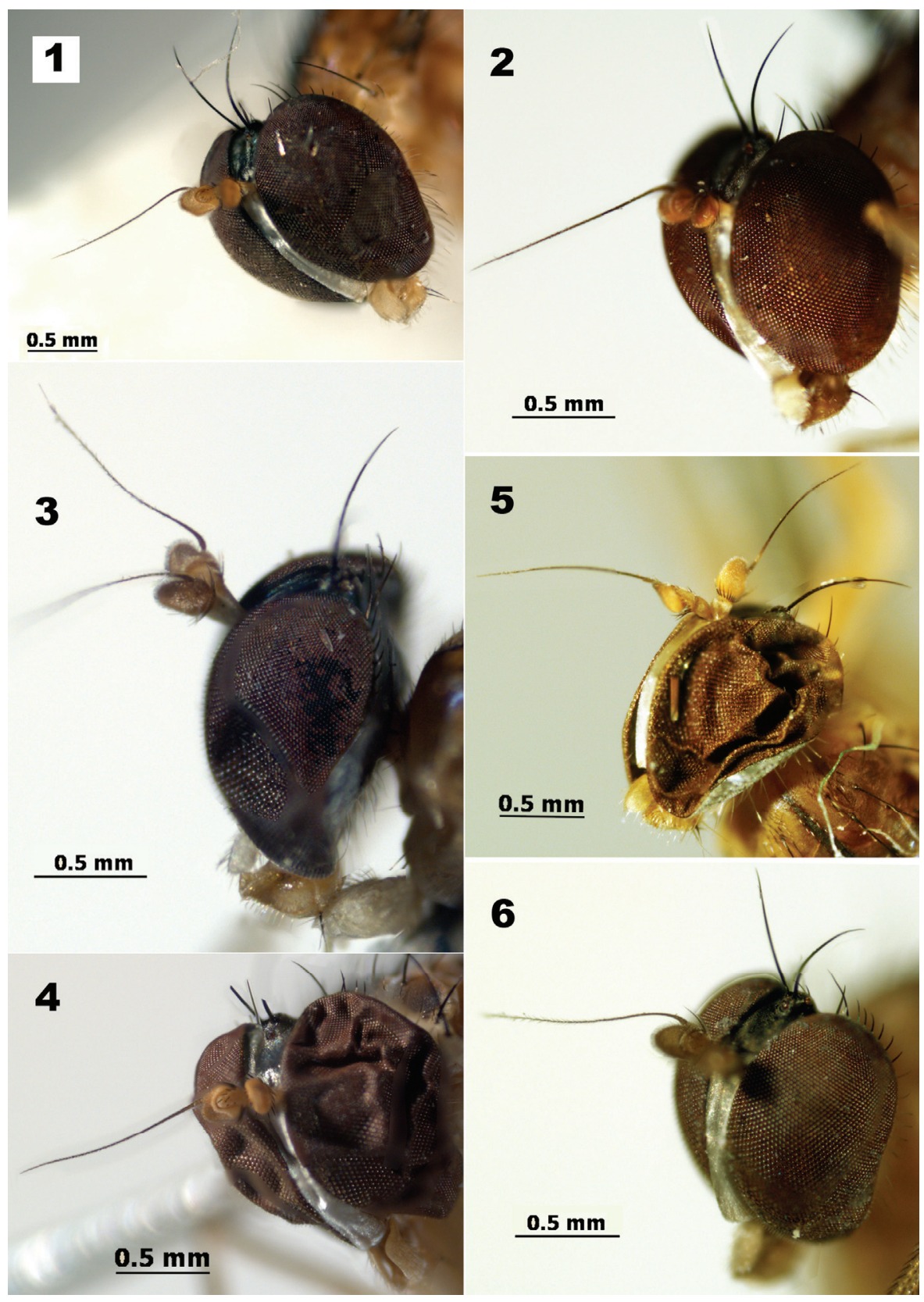

Figs 1-6. Tenuopus spp., head: $1-T$. bururiensis sp. n.; $2-T$. gorongosaensis sp. n.; 3 T. kirkspriggsi sp. n.; $4-T$. kylei sp. n.; 5 - T. lomholdti sp. n.; 6 - T. unicolor (Becker). 
Thorax: pleura yellow; mesonotum mostly orange-yellow, with median greenish blue stripe half as wide as surface between dorsocentral bristles, wider posteriorly; scutellum greenish blue dorsally; 6 dorsocentral setae with posterior pair shifted laterally; acrostichals biseriate, strong, nearly reaching $5^{\text {th }}$ dorsocentrals; scutellum with 2 strong bristles and 2 short lateral hairs; proepisternum with 2 yellow setae.

Legs yellow; last segments of hind tarsus brown; fore and mid coxae with black hairs anteriorly and 5-7 black apical bristles of various length; hind coxa with one long black outer bristle above middle; fore femur with light fine erect ventral hairs, at most as long as diameter of femur, longer at apex, and 1 long black posteroventral cilia; fore tibia simple, with 1 anterodorsal and 1 posterodorsal at base, 2 dorsals in middle, 1-2 apical setae; basitarsus with 2 dorsals; other tarsomeres simple; claws simple; mid femur with small anterior preapical seta, with white ventral hairs, at most as long as diameter of femur; mid tibia with 3 anterior, 3 posterodorsal, 3 ventral, 34 apical seta; hind femur without long hairs, with 1 strong anterior preapical seta; hind tibia with 3 anterior, 2 dorsal, 6 posterodorsal, 2-3 apical setae. Femur, tibia and tarsomere (from first to fifth) length ratio: fore leg: 14/16/18/10/7/3/2, mid leg: 17/25/17/8/6/3/1, hind leg: 14/25/9/8/5/2/1.

Wing greyish, almost hyaline, veins brown; subcosta very thin; ratio of part of costa between $R_{2+3}$ and $R_{4+5}$ to that between $R_{4+5}$ and $M_{1}, 11 / 1 ; M_{1}$ with gentle arc to apex, reaching costa right before wing apex; $\mathrm{M}_{2}$ present as fold on membrane; crossvein $d m-m$ straight; ratio of crossvein $d m-m$ to apical part of $\mathrm{M}_{1+2}$ (fork-handle) to apical part of $\mathrm{M}_{4}, 4 / 12 / 10$; anal vein foldlike, not reaching wing margin; anal angle obtuse; lower calypter yellow, with black apex and pale setae; halter yellow with orange knob, halter stem thin and long, with dorsal and ventral groups of short hairs distally.

Abdomen mostly yellow-orange, black setose; $2^{\text {nd }}-5^{\text {th }}$ yellow, with narrow black posterior edging; $6^{\text {th }}, 8^{\text {th }}$ segment and epandrium entirely yellow; $8^{\text {th }}$ segment with yellow hairs; cerci and surstyli yellow; surstylus and epandrial lobe black at apex; cercus covered with dark-yellow hairs and setae; hypandrium small, simple; phallus thin and simple; epandrial lobe prominent, somewhat expanded distally, with 3 apical setae; 2 pedunculate epandrial setae of different length and 3 fused epandrial processes between hypandrium and base of epandrial lobe, including 1 process with rather long apical seta, 1 process with microscopic apical seta and 1 shorter process with moserately long seta; surstylus about as long as cercus, with apical incision, with thin pointed dorsal and thick ventral lobes; dorsal lobe of surstylus with 1 microscopic apical seta; ventral lobe of surstylus with 1 small inner seta; cercus as long as epandrium, subtriangular, with pointed apex, covered with hairs dorsally and few setae distally.

MEASUREMENTS (in mm). Body length 7.5; antenna length 1.7; wing length 6.6; wing width 1.9.

Female. Unknown.

ETYMOLOGY. The species is named after the type locality.

DISTRIBUTION. Burundi.

DIAGNOSIS. T. bururiensis sp. n. belongs to a group of species with biseriate acrostichals, being the closest to T. fursovi, differing from the latter in male fore tarsus simple, male surstylus broad (see key above). 


\section{Tenuopus cognatus Parent, 1934}

Figs 23-25

MATERIAL EXAMINED. 1 $\delta^{\Uparrow}$, RSA: KZN, Royal Natal Nature Park, Mahai Campsite are at: $28^{\circ} 41.386^{\prime} \mathrm{S}, 2^{\circ} 56.288^{\prime} \mathrm{E}, 17-18$.II 2010, A.H. Kirk-Spriggs / Malaise trap (1), straddling Mahai River [BMSA]; 1 , RSA, [Eastern Cape,] Tsitsikamma N.P., Plaatbos Nat. reserve at: 3956.137'S, 2354.895'E, 20-22.I 2009, A.H. Kirk-Spriggs \& S. Otto / malaise trap, indigenous forest [BMSA].

DISTRIBUTION. Type locality: South Africa: Natal, Kloof. South Africa.

NOTES. The species was originally illustrated with a line drawing of wing only. I publish here pictures of the male head and hypopygium for the first time. Tenuopus cognatus is remarkable in having long male cerci clinging close to each other and forming a flat tongue (dorsal view).

\section{Tenuopus erroneus Parent, 1934}

MATERIAL EXAMINED. 19 (in ethanol), South Africa: KZN, Ramsgate, Butterfly sanctuary, $30^{\circ} 53.3^{\prime} \mathrm{S} / 30^{\circ} 20.4^{\prime} \mathrm{E}, 27 . \mathrm{IV}-27$.VII 2005 , MT nr. stream, M. Mostovski [NMSA]; 1 ㅇ (in ethanol), South Africa: KZN, Cathedral Peak Nat. Res., Rainbow Gorge, 1480 m, 2857.60'S, 29¹3.61'E, 14.XII 2005-29.I 2006, MT, M. Mostovski [NMSA].

DISTRIBUTION. Type locality: South Africa: Cape Province, Mossel Bay. South Africa.

Tenuopus gorongosaensis Grichanov, sp. n.

Figs 2, 9, 16, 17

TYPE MATERIAL. Holotype - $\hat{\jmath}$, [Mozambique:] Gorongosa mountain, Manica-Sofala Dist., Port. East Africa, 840 m, gallery forest, IX 1957, Stuckenberg [NMSA]. Paratypes: 1§̃, 1 , , same label [NMSA].

DESCRIPTION. Male. Head: frons black, grey pollinose; one pair of short postvertical setae, as long as uppermost postocular seta; upper postocular setae black, increasing in length upward; lateral and lower postoculars white; ventral postcranium covered with irregular white hairs; face silvery-white, 7 times as high as wide in middle, nearly as wide as postpedicel; clypeus slightly bulging; antennae as long as height of head, with yellow scape and pedicel and yellow-brown postpedicel; pedicel projected distally on inner side, with a crown of short black setae, one of dorsal setae as long as pedicel; postpedicel rounded, as long as high at base (1/1); arista-like stylus dorsal, with short hairs; length ratio of scape to pedicel to postpedicel to stylus ( $1^{\text {st }}$ and $2^{\text {nd }}$ segments), 5/5/6/2/32; palpus and proboscis short, yellow, covered with white hairs, proboscis also with a pair of black lateral setae.

Thorax: pleura dirty yellow; mesonotum brownish orange, with narrow black stripe along acrostichals, wider posteriorly and black on scutellum dorsally; 6 dorsocentral setae with posterior pair shifted laterally; acrostichals irregularly biseriate, short, nearly reaching $5^{\text {th }}$ dorsocentrals; scutellum with 2 strong bristles and 2 short lateral hairs; proepisternum with 2 yellow setae. 
Legs yellow; last segments of tarsi brown; fore and mid coxae with black hairs anteriorly and 5-7 black apical bristles of various length; hind coxa with one long black outer bristle above middle; fore femur with only few light fine erect ventral hairs on basal half, and 3 short black posteroventral cilia; fore tibia simple, with 1 anterodorsal and 1 posterodorsal at base, 1-2 apical setae; $3^{\text {rd }}$ to $5^{\text {th }}$ segments with posteroventral row of short semi-erect setulae; claws simple; mid femur with strong anterior preapical seta, practically glabrous ventrally, with microscopic white ventral hairs; mid tibia with 4 anterior, 4 posterodorsal, 3-5 ventral, $4-5$ apical setae; mid basitarsus with several short ventral setae; hind femur without long hairs, with 1 strong anterior preapical seta; hind tibia with 5 anterior, 5 posterodorsal, 3-4 apical setae. Femur, tibia and tarsomere (from first to fifth) length ratio: fore leg: 10/11/9/4/3/2/1, mid leg: 13/18/13/5/4/2/1, hind leg: 14/23/9/6/4/2/1.

Wing greyish, almost hyaline, veins brown; subcosta very thin; ratio of part of costa between $R_{2+3}$ and $R_{4+5}$ to that between $R_{4+5}$ and $M_{1}, 6 / 1 ; M_{1}$ with gentle arc to apex, reaching costa right before wing apex; $\mathrm{M}_{2}$ present as fold on membrane; crossvein $d m-m$ straight; ratio of crossvein $d m-m$ to apical part of $\mathrm{M}_{1+2}$ (fork-handle) to apical part of $\mathrm{M}_{4}, 4 / 11 / 13$; anal vein foldlike, not reaching wing margin; anal angle obtuse; lower calypter yellow, with black apex and pale setae; halter yellow with orange knob, halter stem thin and long, with dorsal and ventral groups of short hairs distally.

Abdomen mostly yellow-orange, black setose; $1^{\text {st }}$ segment yellow, with narrow black posterior edging; $2^{\text {nd }}-5^{\text {th }}$ yellow, with narrow black posterior edging and broad black triangular spot anteriorly; $6^{\text {th }}$ mostly black, yellow distally; $8^{\text {th }}$ segment and epandrium entirely yellow; $8^{\text {th }}$ segment with yellow hairs; cercus and dorsal surstylus yellow, ventral surstylus brown; cercus covered with dark-yellow hairs and setae; hypandrium small, simple; phallus thin and simple; 2 epandrial lobes distally on each side; thick epandrial lobe with 3 apical setae; thin epandrial lobe with 2 apical setae; short epandrial seta close to epandrial lobes; 1 short and 1 long epandrial setae at base of hypandrium; surstylus about as long as cercus, divided in 2 lobes from base, with both lobes curved towards longitudinal axis of hypopygium; ventral lobe of surstylus with 1 short apical spine; cercus half as long as epandrium, spatulate, slightly expanded distally, covered with long hairs dorsally and distally.

MEASUREMENTS (in mm). Body length 6.3; antenna length 1.3; wing length 5; wing width 1.5 .

Female. Similar to male except lacking male secondary sexual characters. Face wider; legs simple; femur, tibia and tarsomere (from first to fifth) length ratio: fore leg: 9/10/9/5/3/2/1, mid leg: 10/16/11/5/3/1.5/1, hind leg: 13/22/8/6/4/2/1.

MEASUREMENTS (in mm). Body length 6.9; wing length 6.1; wing width 2.

ETYMOLOGY. The species is named after the type locality.

DISTRIBUTION. Mozambique.

DIAGNOSIS. T. gorongosaensis sp. n. belongs to a group of species with biseriate acrostichals, being the closest to T. kirkspriggsi sp. n., differing from the latter in male cercus half as long as epandrium, subtriangular (see key above). Female is close to T. taitensis, differing from the latter in hind tibia and basal half of hind basitarsus yellow (see key above). 


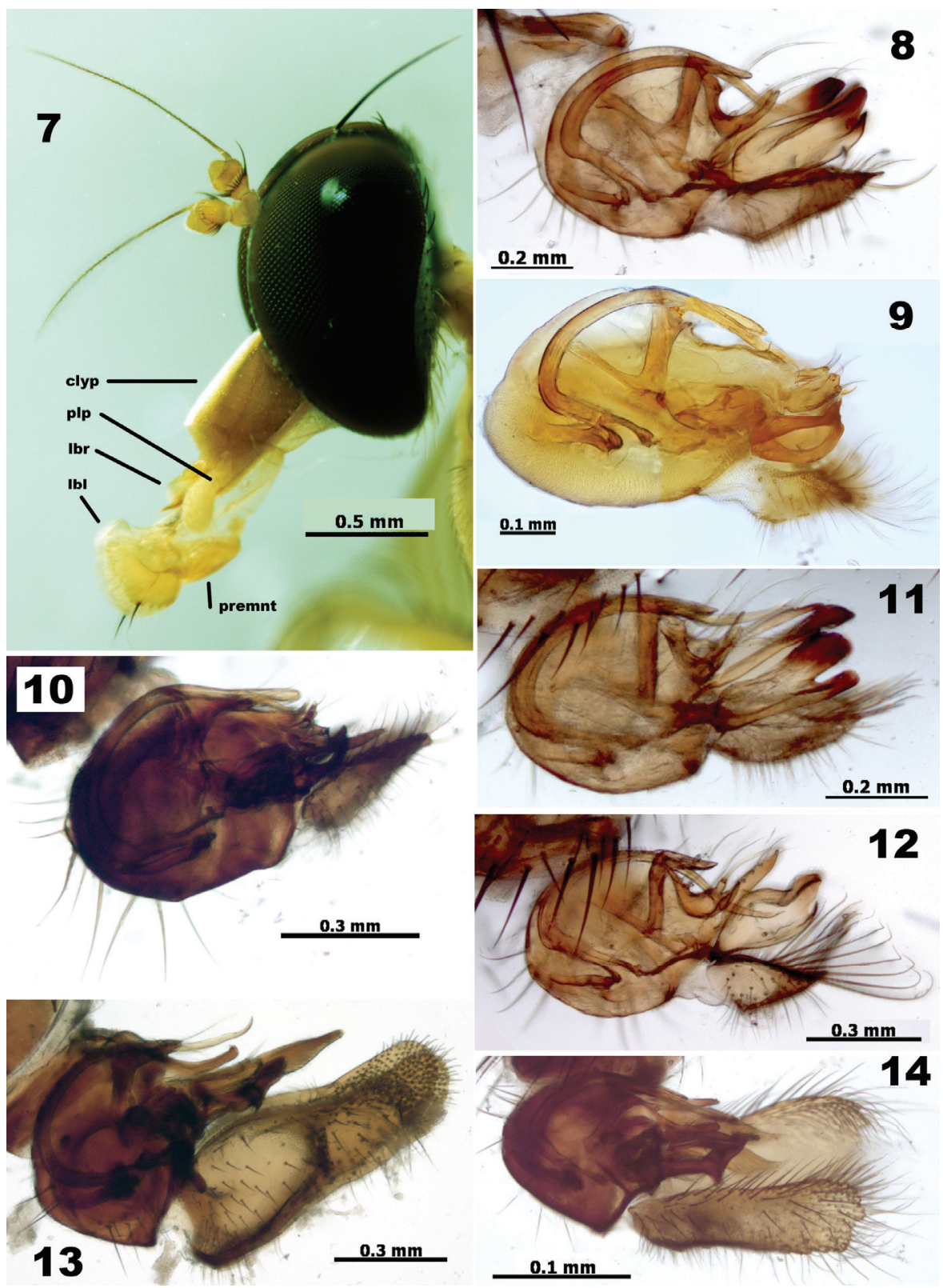

Figs 7-14. Tenuopus spp. 7 - T. shcherbakovi Grichanov, head in ethanol with everted mouthparts (abbreviations: clyp - clypeus; lbl - labellum; lbr - labrum; plp - palpus; premnt prementum); 8-14-hypopygium after maceration, right lateral view: $8-T$. bururiensis $\mathrm{sp} . \mathrm{n}$; $9-$ T. gorongosaensis sp. n.; $10-$ T. kirkspriggsi sp. n.; $11-$ T. kylei sp. n.; $12-$ T. lomholdti sp. n.; 13 - T. shcherbakovi Grichanov; $14-$ T. unicolor (Becker). 


\section{Tenuopus guttatus Parent, 1939}

MATERIAL EXAMINED. $1 \hat{\sigma}^{\hat{-}}$ (in ethanol), [DR Congo:] Zaire, Mt. Ilimu, Kivu Prov., $1^{\circ} 50^{\prime}$ S, $28^{\circ} 25^{\prime}$ E, 900-1000 m, [X 1993], fogging Carapa grandiflora, Th. Wagner [NMSA].

DISTRIBUTION. Type locality: Ghana: “Obuasi Ashanti”. DR Congo, Ghana, Ivory Coast.

Tenuopus kirkspriggsi Grichanov, sp. $\mathbf{n}$.

Figs 3, 10, 18

TYPE MATERIAL. Holotype - $\hat{\jmath}$, Burundi: Kayanza Prov., Parc National de la Kibira, Rwegura Sector, $2^{\circ} 55.320^{\prime}$ 'S, $29^{\circ} 30.067^{\prime}$ E, 2237 m, 21-26.XI 2010, A.H. Kirk-Spriggs / malaise trap, indigenous Afromontane forest [BMSA].

DESCRIPTION. Male. Head: frons metallic blue-black, weakly pollinose; one pair of short postvertical setae, as long as uppermost postocular seta; upper postocular setae black, increasing in length upward; lateral and lower postoculars white; ventral postcranium covered with irregular white hairs; face silvery-white, 6 times as high as wide in middle, nearly as wide as postpedicel; clypeus slightly bulging; antennae as long as height of head, with yellow scape and pedicel and yellow-brown postpedicel; pedicel projected distally on inner side, with a crown of short black setae, one of dorsal setae as long as pedicel; postpedicel rounded-oval, slightly longer than high at base (1.6/1.3); arista-like stylus dorsal, with short hairs; length ratio of scape to pedicel to postpedicel to stylus ( $1^{\text {st }}$ and $2^{\text {nd }}$ segments), 4/5/8/3/34; palpus and proboscis short, yellow, covered with white hairs, proboscis also with a pair of black lateral setae.

Thorax: pleura yellow; mesonotum orange, with almost all the surface between dorsocentrals blue-green; scutellum dorsally mostly metallic blue-green; 6 dorsocentral setae with posterior pair shifted laterally; acrostichals biseriate, strong, nearly reaching $5^{\text {th }}$ dorsocentrals; scutellum with 2 strong bristles and 2 short lateral hairs; proepisternum with 2 yellow setae.

Legs yellow, slightly darkened distally; tarsi brown from tip of basitarsus; fore and mid coxae with black hairs anteriorly and 5-7 black apical bristles of various length; hind coxa with one long black outer bristle above middle; fore femur with numerous dark and light fine erect ventral hairs, at most half as long as diameter of femur, and 3 long black posteroventral cilia; fore tibia simple, with elongate ventral hairs and posterior setulae, 1 anterodorsal and 1 posterodorsal at base, 1-2 apical setae; tarsomeres covered with dense hairs ventrally, elongate setulae dorsally; claws simple; mid femur with strong anterior preapical seta, with erect black ventral hairs, at most half as long as diameter of femur; mid tibia with 3 anterior, 3 posterodorsal, 3-5 ventral, 4-5 apical setae; mid basitarsus with several short ventral setae; hind femur without long hairs, with 1 strong anterior preapical seta; hind tibia with 3-4 anterior, 2 anterodorsal, 2 posterodorsal, 3-4 apical setae. Femur, tibia and tarsomere (from first to fifth) length ratio: fore leg: 38/46/38/25/19/11/5, mid leg: 43/72/36/ 16/14/7/4, hind leg: 46/71/18/21/11/7/4. 
Wing greyish, almost hyaline, veins brown; subcosta very thin; ratio of part of costa between $R_{2+3}$ and $R_{4+5}$ to that between $R_{4+5}$ and $M_{1}, 14 / 3 ; M_{1}$ with gentle arc to apex, reaching costa right before wing apex; $\mathrm{M}_{2}$ present as fold on membrane; crossvein $d m-m$ straight; ratio of crossvein $d m-m$ to apical part of $\mathrm{M}_{1+2}$ (fork-handle) to apical part of $\mathrm{M}_{4}, 7 / 23 / 19$; anal vein foldlike, not reaching wing margin; anal angle obtuse; lower calypter yellow, with black apex and pale setae; halter yellow, halter stem thin and long, with dorsal and ventral groups of short hairs distally.

Abdomen mostly yellow-orange, black setose; $1^{\text {st }}$ segment yellow, with triangular black posterior spot dorsally; $2^{\text {nd }}-6^{\text {th }}$ yellow, with broad black edging posteriorly and with small brown dorsal spot anteriorly; $8^{\text {th }}$ segment and epandrium entirely black; cercus and epandrial lobes orange-brown; surstylus black; cercus covered with dark-yellow hairs and setae; hypandrium small, simple; phallus thin and simple; ventral epandrial lobes reduced to short lobules or pedunculate setae; distoventral epandrial lobe prominent, narrow, with 3 minute setae in distal half; surstylus about half as long as cercus, simple, strongly sclerotised, curved; cercus about half as long as epandrium, subtriangular, covered with yellow-brown hairs and setae.

MEASUREMENTS (in mm). Body length 6.3; antenna length 1.3; wing length 6.3; wing width 1.9.

Female. Unknown.

ETYMOLOGY. The species is named after the South African entomologist, Dr. A.H. Kirk-Spriggs (BMSA), the collector of the type specimen.

DISTRIBUTION. Burundi.

DIAGNOSIS. T. kirkspriggsi sp. n. belongs to a group of species with biseriate acrostichals, being the closest to $T$. gorongosaensis $\mathrm{sp}$. n., differing from the latter in male cercus as long as epandrium, swollen at base, narrow at apex (see key above).

Tenuopus kylei Grichanov, sp. n.

Figs 4, 11, 19

TYPE MATERIAL. Holotype - $\hat{\jmath}$, South Africa: Kwazulu, Madlangula, Kosi Bay, 21.I - 6.II 1985, R. Kyle [NMSA]. Paratype: 1 $\hat{\jmath}$, same label [NMSA].

DESCRIPTION. Male. Head: frons black, whitish pollinose; one pair of short postvertical setae, as long as uppermost postocular seta; upper postocular setae black, increasing in length upward; lateral and lower postoculars white; ventral postcranium covered with irregular white hairs; face silvery-white, 7 times as high as wide in middle, nearly as wide as postpedicel; clypeus slightly bulging; antennae as long as height of head, with yellow scape and pedicel and yellow-orange postpedicel; pedicel projected distally on inner side, with a crown of short black setae, one of dorsal setae as long as pedicel; postpedicel rounded, as long as high at base $(1 / 1)$; arista-like stylus dorsal, with short hairs; length ratio of scape to pedicel to postpedicel to stylus ( $1^{\text {st }}$ and $2^{\text {nd }}$ segments), 5/7/9/3/40; palpus and proboscis short, yellow, covered with white hairs, proboscis also with a pair of black lateral setae.

Thorax: pleura yellow; mesonotum mostly orange-yellow, with median greenish blue stripe half as wide as surface between dorsocentral bristles, wider posteriorly and black on scutellum dorsally; 6 dorsocentral setae with posterior pair shifted 
laterally; acrostichals biseriate, strong, nearly reaching $5^{\text {th }}$ dorsocentrals; scutellum with 2 strong bristles and 2 short lateral hairs; proepisternum with 2 yellow setae.

Legs yellow; last segments of hind tarsus brown; fore and mid coxae with black hairs anteriorly and 5-7 black apical bristles of various length; hind coxa with one long black outer bristle above middle; fore femur with light and dark fine erect ventral hairs, at most half as long as diameter of femur, and 1-2 black posteroventral cilia; fore tibia simple, with 1 anterodorsal and 1 posterodorsal at base, 1 dorsal in middle, 1-2 apical setae; basitarsus with 1 dorsal; other tarsomeres simple; claws simple; mid femur with very small anterior preapical seta, practically glabrous ventrally, with few dark ventral hairs; mid tibia with 3 anterior, 3 posterodorsal, 3 ventral, 3-4 apical seta; hind femur without long hairs, with 1 strong anterior preapical seta; hind tibia with 3 anterior, 2 dorsal, 3 posterodorsal, 2-3 apical setae. Femur, tibia and tarsomere (from first to fifth) length ratio: fore leg: 9/12/15/8/4/2/1, mid leg: 10/15/12/5/4/2/1, hind leg: 12/20/6/6/4/2/1.

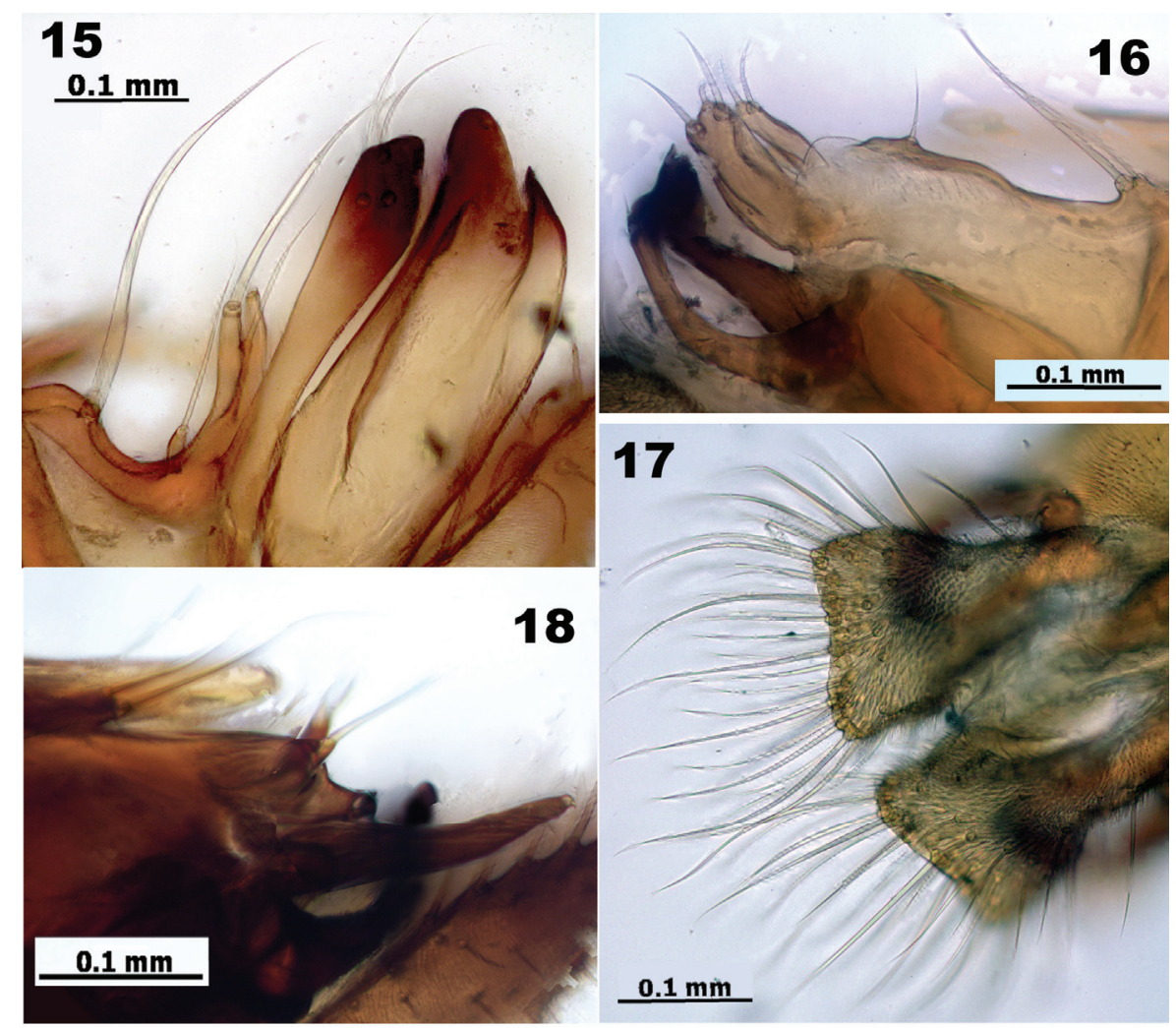

Figs 15-18. Tenuopus spp., epandrial lobes and surstylus, right $(15,18)$ and left $(16)$ lateral view, and cercus, dorsal view (17): $15-T$. bururiensis sp. n.; 16-17-T. gorongosaensis sp. $\mathrm{n}$.; $18-T$. kirkspriggsi sp. $\mathrm{n}$. 
Wing greyish, almost hyaline, veins brown; subcosta very thin; ratio of part of costa between $R_{2+3}$ and $R_{4+5}$ to that between $R_{4+5}$ and $M_{1}, 7 / 1 ; M_{1}$ with gentle arc to apex, reaching costa right before wing apex; $\mathrm{M}_{2}$ present as fold on membrane; crossvein $d m-m$ straight; ratio of crossvein $d m-m$ to apical part of $\mathrm{M}_{1+2}$ (fork-handle) to apical part of $\mathrm{M}_{4}, 5 / 16 / 13$; anal vein foldlike, not reaching wing margin; anal angle obtuse; lower calypter yellow, with black apex and pale setae; halter yellow with orange knob, halter stem thin and long, with dorsal and ventral groups of short hairs distally.

Abdomen mostly yellow-orange, black setose; $2^{\text {nd }}-6^{\text {th }}$ yellow, with narrow brown or black anterior and posterior edging; $8^{\text {th }}$ segment and epandrium entirely yellow; $8^{\text {th }}$ segment with yellow hairs; cerci and surstyli yellow; surstylus and epandrial lobe black at apex; cercus covered with dark-yellow hairs and setae; hypandrium small, simple; phallus thin and simple; epandrial lobe prominent, finger-like, narrow at apex, with 2 ventral setae; 3 pedunculate epandrial setae of different length and 2 epandrial processes between hypandrium and base of epandrial lobe, including 1 process with rather long apical seta and 1 slightly longer process with microscopic apical seta; surstylus about as long as cercus, with apical incision, with thin dorsal and thick ventral lobes; dorsal lobe of surstylus with 1 small apical seta; ventral lobe of surstylus with 2 small apical setae; cercus nearly as long as epandrium, subtriangular, covered with hairs dorsally and setae distally.

MEASUREMENTS (in mm). Body length 6.0; antenna length 1.4; wing length 5.1; wing width 1.6.

Female. Unknown.

ETYMOLOGY. The species is named after the South African zoologist, Dr. R. Kyle (Ezemvelo KwaZulu Natal Wildlife), the collector of the type specimens.

DISTRIBUTION. South Africa.

DIAGNOSIS. T. kylei sp. n. belongs to a group of species with biseriate acrostichals, being the closest to T. kononenkoi, differing from the latter in male fore basitarsus longer, about 1.3 times as long as fore tibia; and male surstylus bifurcated only at apex, with broad lobes (see key above).

\section{Tenuopus lomholdti Grichanov, sp. n.}

TYPE MATERIAL. Holotype - $\hat{\jmath}$, Tanzania: East Uzambara, Amani, $1000 \mathrm{~m}$, 26.I 1977, H. Enghoff, O. Lomholdt \& O. Martin leg. [ZMUC]. Paratype: $1 \delta^{\Uparrow}$ (in ethanol), Tanzania: Morogoro Reg., Udzungwa Mt. N. P., Mito Mitatu, 750'15.1"S, 3650'49.9"E, 1198 m, Malaise trap, 17.V 2013, T. Pape \& N. Scharff leg. [ZMUC].

DESCRIPTION. Male. Head: frons black, whitish pollinose; one pair of short postvertical setae, as long as uppermost postocular seta; upper postocular setae black, increasing in length upward; lateral and lower postoculars white; ventral postcranium covered with irregular white hairs; face silvery-white, 7 times as high as wide in middle, nearly as wide as postpedicel; clypeus slightly bulging; antennae as long as height of head, with yellow scape and pedicel and yellow-orange postpedicel; pedicel projected distally on inner side, with a crown of short black setae, one of dorsal setae as long as pedicel; postpedicel rounded, slightly longer than high at base (1.5/1.3); arista-like stylus dorsal, with short hairs; length ratio of scape to 
pedicel to postpedicel to stylus ( $1^{\text {st }}$ and $2^{\text {nd }}$ segments), $15 / 17 / 20 / 12 / 92$; palpus and proboscis short, yellow, covered with white hairs, proboscis also with a pair of black lateral setae.

Thorax: pleura dirty yellow; mesonotum brownish orange, with narrow black stripe along acrostichals, wider posteriorly and black on scutellum dorsally; 6 dorsocentral setae with posterior pair shifted laterally; acrostichals irregularly biseriate, short, nearly reaching $5^{\text {th }}$ dorsocentrals; scutellum with 2 strong bristles and 2 short lateral hairs; proepisternum with 2 yellow setae.

Legs yellow; last segments of tarsi brown; fore and mid coxae with black hairs anteriorly and 5-7 black apical bristles of various length; hind coxa with one long black outer bristle above middle; fore femur with dark fine erect ventral hairs, at most half as long as diameter of femur, and 1-2 black posteroventral cilia; fore tibia simple, with 1 anterodorsal and 1 posterodorsal at base, 1-2 dorsals in middle, 1-2 apical setae; tarsomeres simple, with rather short ventral semi-erect setulae on all segments, with 1-2 elongate dorsal setae on distal apex of segments 1-4; claws simple; mid femur with very small anterior preapical seta, glabrous ventrally; mid tibia with 3 anterior, 3 posterodorsal, 3 ventral, 3-4 apical seta; basitarsus with few short ventral setae; hind femur without long hairs, with 1 strong anterior preapical seta; hind tibia with 3 anterior, 2 dorsal, 3 posterodorsal, 2-3 apical setae; basitarsus with few short posterior setae. Femur, tibia and tarsomere (from first to fifth) length ratio: fore leg: 44/45/35/19/19/21/12, mid leg: 31/50/35/15/11/6/4, hind leg: 28/51/17/15/10/6/3

Wing greyish, veins brown; subcosta very thin; ratio of part of costa between $\mathrm{R}_{2+3}$ and $\mathrm{R}_{4+5}$ to that between $\mathrm{R}_{4+5}$ and $\mathrm{M}_{1}, 16 / 2 ; \mathrm{M}_{1}$ with gentle arc to apex, reaching costa right before wing apex; $\mathrm{M}_{2}$ present as fold on membrane; crossvein $d m-m$ straight; ratio of crossvein $d m-m$ to apical part of $\mathrm{M}_{1+2}$ (fork-handle) to apical part of $\mathrm{M}_{4}, 9 / 31 / 23$; anal vein foldlike, not reaching wing margin; anal angle obtuse; lower calypter yellow, with black apex and pale setae; halter yellow with orange knob, halter stem thin and long, with dorsal and ventral groups of short hairs distally.

Abdomen mostly yellow-orange, black setose; $2^{\text {nd }}-6^{\text {th }}$ yellow, with narrow brown or black posterior edging; $8^{\text {th }}$ segment and epandrium entirely yellow; $8^{\text {th }}$ segment with dark hairs; cerci and surstyli yellow; cercus covered with dark-yellow hairs and setae; surstylus dark at apex; hypandrium small, simple; phallus thin and simple; epandrial lobe prominent, finger-like, pointed at apex, with 4 ventral setae; 5 epandrial setae of different length between hypandrium and base of epandrial lobe, including 1 thick pedunculate seta; surstylus about as large as cercus, irregularly leaf-like, with small dorsal process at apex, with 2 inner setae at middle; cercus about half as long as epandrium, subtriangular, pointed at apex, covered with short hairs dorsally, double row of long setae distally.

MEASUREMENTS (in mm). Body length 5.8; antenna length 1.3; wing length 4.9; wing width 1.4.

Female. Unknown.

ETYMOLOGY. The species is named after the Danish entomologist, Dr. O. Lomholdt (ZMUC), one of the collectors of the type specimens.

DISTRIBUTION. Tanzania. 
DIAGNOSIS. T. lomholdti sp. $\mathrm{n}$. belongs to a group of species with biseriate acrostichals, being the closest to $T$. taitensis due to enlarged surstylus, differing from the latter in male cercus subtriangular, without process, surstylus about as large as cercus (see key above).

\section{Tenuopus maculatus Parent, 1931}

MATERIAL EXAMINED. 19 , Tanzania: Morogoro env., Uluguru Mts., $6.84593^{\circ} \mathrm{S}, 37.692^{\circ} \mathrm{E}, 853 \mathrm{~m}, 17 . \mathrm{IX} 2012$, D. Gavryushin [ZMUM].

DISTRIBUTION. Type locality: Malawi: Mt. Mlange. Kenya, Malawi, Tanzania.

Tenuopus shcherbakovi Grichanov, 1996

Figs $7,13,21$

MATERIAL EXAMINED. $1 \delta^{\Uparrow}$ (dried from ethanol and mounted on pin), Kenya: Kakamega Forest, $0^{\circ} 22^{\prime} \mathrm{S}, 3^{\circ} 50^{\prime} \mathrm{E}, 1500$ m, 3.VI 2000, white pantrap, M. Kraemer \& G. Velten [NMSA]; 19, Tanzania: East Uzambara, Amani, 1000 m, 1.II 1977, H. Enghoff, O. Lomholdt, O. Martin [ZMUC].

DESCRIPTION. Male (somewhat discolorated). Head: frons black, pollinose; one pair of well developed postvertical setae; upper postocular setae black, slightly increasing in length upward; lateral and lower postoculars white; ventral postcranium covered with irregular white hairs; face silvery-white, 7 times as high as wide in middle, nearly as wide as postpedicel; clypeus bulging; antennae as long as height of head, with yellow scape and pedicel and orange postpedicel; pedicel projected distally on inner side, with a crown of short black setae, one of dorsal setae as long as pedicel; postpedicel subtriangular, as long as high (1/1); arista-like stylus dorsal, with short hairs; length ratio of scape to pedicel to postpedicel to stylus $\left(1^{\text {st }}\right.$ and $2^{\text {nd }}$ segments), 4/5/5/2/34; palpus and proboscis short, yellow, covered with white hairs, proboscis also with a pair of black lateral setae.

Thorax: pleura yellow; mesonotum orange, dark medially on posterior part; scutellum dorsally mostly metallic blue-green; 6 dorsocentral setae with posterior pair shifted laterally; acrostichals uniseriate, strong, nearly reaching $5^{\text {th }}$ dorsocentrals; scutellum with 2 strong bristles and 2 short lateral hairs; proepisternum with 1 long and 1 short brown setae.

Legs yellow, slightly darkened distally; tarsi brown from tip of basitarsus; fore and mid coxae with black hairs anteriorly and 5-7 black apical bristles of various length; hind coxa with one long black outer bristle above middle; fore femur with numerous dark fine erect ventral hairs, at most half as long as diameter of femur, and 3 long black posteroventral cilia; fore tibia simple, with elongate ventral and posterior setulae, 1 anterodorsal and 1 posterodorsal at base, 1-2 dorsals in middle, 1-2 apical setae; basitarsus with elongate setulae ventrally, slightly thickened at apex; apical half of $2^{\text {nd }}, 3^{\text {rd }}$ to $5^{\text {th }}$ segments with posteroventral row of strong erect setulae; $2^{\text {nd }}$ to $4^{\text {th }}$ segments with 1-2 short dorsoapical setae; claws simple; mid femur with 
strong anterior preapical seta, with semi-erect black ventral hairs in distal half, at most half as long as diameter of femur; mid tibia with 3 anterior, 3 posterodorsal, 3-5 ventral, 4-5 apical setae; mid basitarsus with several short ventral setae; hind femur without long hairs, with 1 strong anterior preapical seta; hind tibia with 3-4 anterior, 2 anterodorsal, 2 posterodorsal, 3-4 apical setae. Femur, tibia and tarsomere (from first to fifth) length ratio: fore leg: 11/12/8/6/2/3/3, mid leg: 10/15/9/4/3/2/1, hind leg: $12 / 20 / 5 / 6 / 3 / 2 / 1$.

Wing greyish, veins brown; subcosta very thin; ratio of part of costa between $\mathrm{R}_{2+3}$ and $\mathrm{R}_{4+5}$ to that between $\mathrm{R}_{4+5}$ and $\mathrm{M}_{1}, 5 / 1 ; \mathrm{M}_{1}$ with gentle arc to apex, reaching costa right before wing apex; $\mathrm{M}_{2}$ present as fold on membrane; crossvein $d m-m$ straight; ratio of crossvein $d m-m$ to apical part of $\mathrm{M}_{1+2}$ (fork-handle) to apical part of $\mathrm{M}_{4}, 3 / 8 / 8$; anal vein foldlike, not reaching wing margin; anal angle obtuse; lower calypter yellow, with brown apex and pale setae; halter yellow with white knob, halter stem thin and long, with dorsal and ventral groups of short hairs distally.
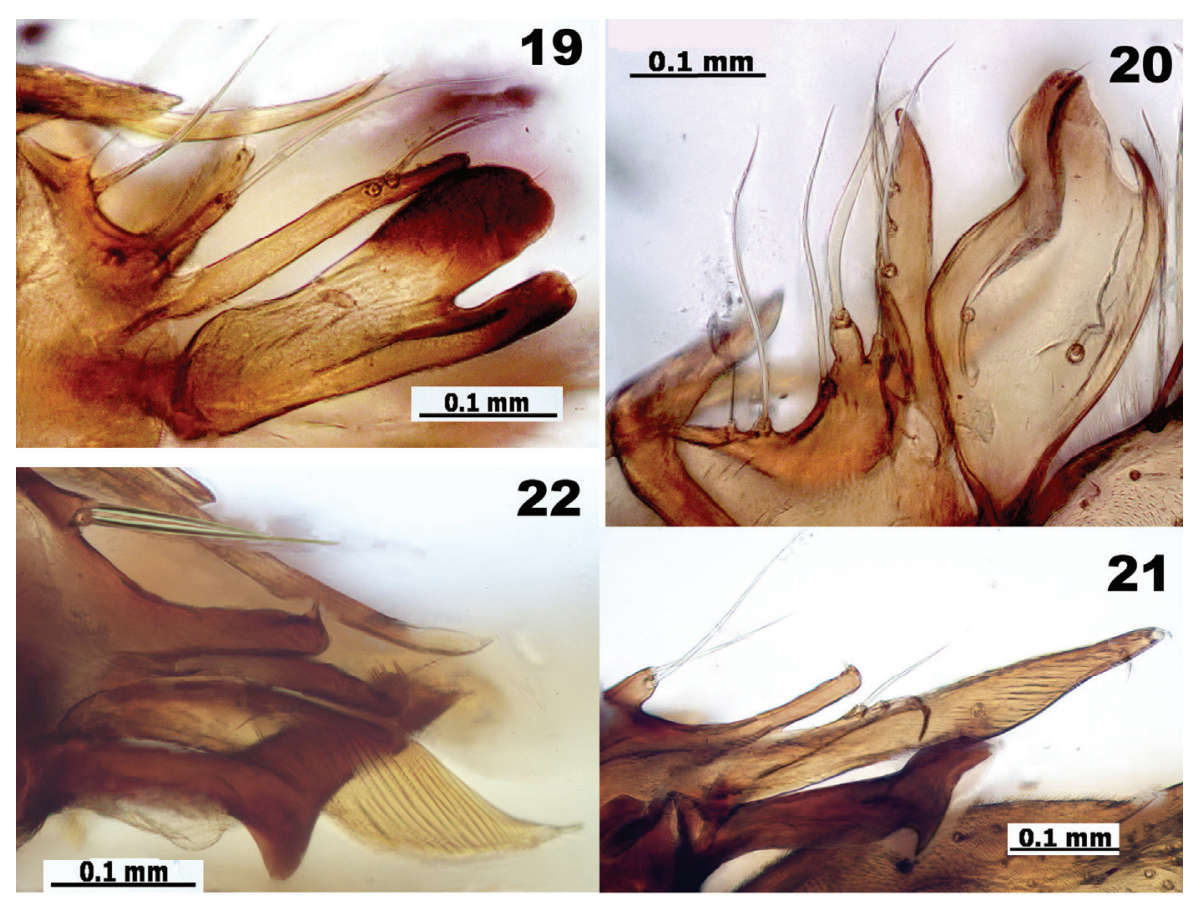

Figs 19-22. Tenuopus spp., epandrial lobes and surstylus, right lateral view: $19-$ T. kylei sp. n.; 20 - T. lomholdti sp. n.; $21-$ T. shcherbakovi Grichanov; $22-$ T. unicolor (Becker).

Abdomen mostly yellow, black setose; $1^{\text {st }}$ segment yellow; $2^{\text {nd }}-5^{\text {th }}$ yellow, with narrow black edgings posteriorly; $6^{\text {th }}, 8^{\text {th }}$ segments and epandrium almost entirely black; epandrial lobes brown; hypandrium small, simple; phallus thin and simple; 1 
short epandrial lobe bearing 2 long apical setae at base of hypandrium; 1 long epandrial lobe distally with 2 arms, with proximal arm bearing minute apical seta and distal arm bearing long apical seta; 1 thin distoventral lobe, as long as bifurcated lobe, bearing 2 short and 1 long setae at apex; 1 very long sword-shaped distoventral lobe, as long as epandrium, bearing 3 short setae, i.e. 1 apical, 1 subapical and 1 seta at middle of inner side; surstylus black, long and narrow, nearly half as long as epandrium, bearing 3 minute setae in distal half and strong dorsal tooth at middle; cercus yellow, twice longer than epandrium, elongate-ovate, broadened in basal half, covered with rather short, mostly black hairs, shorter and denser at apex.

MEASUREMENTS (in mm; in ethanol). Body length 7.0; antenna length 1.2; wing length 5.4; wing width 1.5 .

DISTRIBUTION. Type locality: Uganda: Namanve. Kenya, Uganda. This species is recorded here from Tanzania for the first time.

DIAGNOSIS. The species was originally described by a female (Grichanov, 1996). Later, its males and females were recorded by Grichanov et al. (2011a). One of those males is here described for the first time. T. shcherbakovi belongs to a group of species with uniseriate acrostichals, being the closest to $T$. unicolor, differing from the latter in male and female postpedicel subtriangular, as long as high; cercus broadest at base (see key above).

\section{Tenuopus soderlundi Grichanov, sp. n.} Figs 26-28

TYPE MATERIAL. Holotype - $\widehat{\jmath}$, South Africa: Cape Province, $10 \mathrm{~km} \mathrm{~S}$ of Citrusdal, Koomlandskloof, $32^{\circ} 40^{\prime} \mathrm{S}, 19^{\circ} 01^{\prime} \mathrm{E}$, Malaise-trap, at stream in low indigenous forest, 5-8.X 1994, M. Söderlund [ZMLU]. Paratype: 1ठ,, Republic of South Africa: Cape Province, $10 \mathrm{~km} \mathrm{~S}$ of Citrusdal, Koomlandskloof, 32 $42^{\circ} \mathrm{S}$, $19^{\circ} 01^{\prime} \mathrm{E}$, Malaise-trap, fynbos on mountain, 5-7.X 1994, Michael Söderlund [ZMLU].

DESCRIPTION. Male (somewhat discolorated). Head: frons black, shining; one pair of short postvertical setae; upper postocular setae black, slightly increasing in length upward; lateral and lower postoculars white; ventral postcranium covered with irregular white hairs; face silvery-white, 6 times as high as wide in middle, nearly as wide as postpedicel; clypeus bulging; antennae as long as height of head, with yellow scape and pedicel and orange postpedicel; pedicel projected distally on inner side, with a crown of short black setae, 1-2 dorsal setae longer; postpedicel rounded, as long as high (1/1); arista-like stylus dorsal, with short hairs; length ratio of scape to pedicel to postpedicel to stylus ( $1^{\text {st }}$ and $2^{\text {nd }}$ segments), $5 / 6 / 8 / 6 / 39$; palpus and proboscis short, yellow, covered with white hairs, proboscis also with a pair of black lateral setae.

Thorax: pleura yellow; mesonotum orange, with median black stripe half as wide as surface between dorsocentral bristles, wider posteriorly; scutellum black dorsally; 6 dorsocentral setae with posterior pair shifted laterally; acrostichals absent; scutellum with 2 strong bristles and 2 short lateral hairs; proepisternum with 2 long yellow setae. 
Legs including coxae yellow; tarsi brown from tip of basitarsus; fore and mid coxae with black hairs anteriorly and 4-7 black apical bristles of various length; hind coxa with one long black outer bristle above middle; fore leg without remarkable

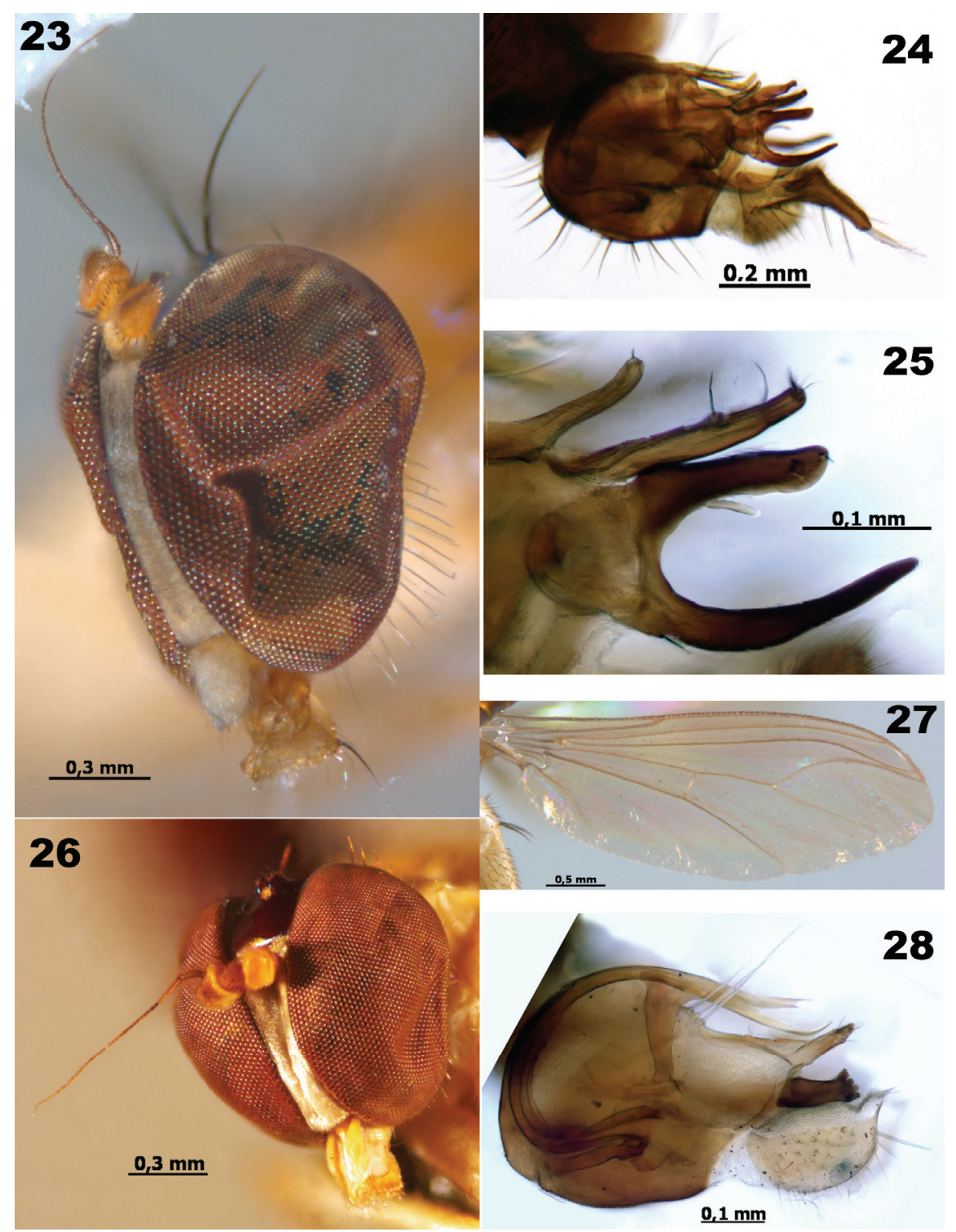

Figs 23-28. Tenuopus spp. 23-25 - T. cognatus Parent; 26-28 - T. soderlundi sp. n.; 23 , 26 - head; 27 - wing; 24, 28 - hypopygium after maceration, right lateral view; 25 - epandrial lobes and surstylus, right lateral view. 
hairs and setae; fore tibia simple, with 1 short anterodorsal at base, 1-2 short apical setae; claws simple; mid femur with strong anterior preapical seta; mid tibia with 23 anterior, 3 posterodorsal, 3-5 ventral, 4-5 apical setae; mid basitarsus with several short ventral setae; hind femur without long hairs, with 1 strong anterior preapical seta; hind tibia with 4-5 anterior, 2 anterodorsal, 2 posterodorsal, 3-4 apical setae. Femur, tibia and tarsomere (from first to fifth) length ratio: fore leg: 13/13/11/5/ 3/2/2, mid leg: 16/21/14/6/4/2/2, hind leg: 19/27/8/9/5/3/2.

Wing hyaline, veins yellow; subcosta very thin; ratio of part of costa between $\mathrm{R}_{2+3}$ and $\mathrm{R}_{4+5}$ to that between $\mathrm{R}_{4+5}$ and $\mathrm{M}_{1}, 4 / 1 ; \mathrm{M}_{1}$ with gentle arc to apex, reaching costa far before wing apex; $\mathrm{M}_{2}$ present as fold on membrane; crossvein $d m-m$ straight; ratio of crossvein $d m-m$ to apical part of $\mathrm{M}_{1+2}$ (fork-handle) to apical part of $\mathrm{M}_{4}, 2.5 / 6 / 11$; anal vein foldlike, not reaching wing margin; anal angle obtuse; lower calypter yellow, with brown apex and pale setae; halter yellow, halter stem thin and long, with dorsal and ventral groups of short hairs distally.

Abdomen mostly yellow, black setose; $1^{\text {st }}$ segment yellow, with white hairs ventrally; $5^{\text {th }}$ segment mostly brown, $6^{\text {th }}$ segment black; epandrium yellow-brown; surstylus and epandrial lobes brown; hypandrium relatively long, simple; phallus thin and simple; basoventral epandrial lobe reduced to 3 long apical setae at base of hypandrium; 1 long epandrial lobe distally with short setae at apex; 2-3 short setae between basoventral and distoventral lobes; surstylus short, about $1 / 3$ as long as epandrium, strongly sclerotised, paw-shaped, with 4 apical processes; cercus yellow, half as long as epandrium, rounded, with short apical projection, covered with short hairs and several setae.

MEASUREMENTS (in mm). Body length 5-5.2; antenna length 1.1; wing length 4.2; wing width 1.4 .

Female. Unknown.

ETYMOLOGY. The species is named after the Swedish entomologist, Dr. M. Söderlund (ZMLU), the collector of the type specimens.

DISTRIBUTION. South Africa.

DIAGNOSIS. T. soderlundi $\mathrm{sp}$. $\mathrm{n}$. is the smallest fly in the genus and belongs to a group of species with uniseriate acrostichals or without acrostichals, being the closest to T. cognatus, differing from the latter in wing vein $\mathrm{M}_{4}$ more than 4 times longer than $d m-m$; abdomen with $2^{\text {nd }}-4^{\text {th }}$ segments entirely yellow (see key above).

\section{Tenuopus unicolor (Becker, 1914)}

Figs 6, 14, 22

Psilopus unicolor Becker, 1914: 126. Type locality: Kenya.

Sciapus unicolor: Becker, 1923: 48.

Tenuopus unicolor: Dyte \& Smith, 1980: 449.

TYPE MATERIAL. Neotype, here designated: $\widehat{\jmath}$, Kenya: Kiambu Co., $0.932^{\circ} \mathrm{S}$, $36.616^{\circ} \mathrm{E}, 2600 \mathrm{~m}, 18 . \mathrm{XII} 2013$, N. Vikhrev [ZMUM].

DESCRIPTION. Male. Head: frons black, densely brownish pollinose; one pair of well developed postvertical setae; upper postocular setae black, increasing in length 
upward; lateral and lower postoculars white; ventral postcranium covered with irregular white hairs; face silvery-white, 5 times as high as wide in middle, nearly as wide as postpedicel; clypeus slightly bulging; antennae as long as height of head, with yellow scape and pedicel and blackish-brown postpedicel; pedicel projected distally on inner side, with a crown of short black setae, one of dorsal setae as long as pedicel; postpedicel rounded-oval, slightly longer than high at base (1.5/1.2); arista-like stylus dorsal, with short hairs; length ratio of scape to pedicel to postpedicel to stylus $\left(1^{\text {st }}\right.$ and $2^{\text {nd }}$ segments), 4/5/6/2/30; palpus and proboscis short, yellow, covered with white hairs, proboscis also with a pair of black lateral setae.

Thorax: pleura yellow; mesonotum orange, dark medially on posterior part; scutellum dorsally mostly metallic blue-green; 6 dorsocentral setae with posterior pair shifted laterally; acrostichals uniseriate, strong, nearly reaching $5^{\text {th }}$ dorsocentrals; scutellum with 2 strong bristles and 2 short lateral hairs; proepisternum with 2 yellow setae.

Legs yellow, slightly darkened distally; tarsi brown from tip of basitarsus; fore and mid coxae with black hairs anteriorly and 5-7 black apical bristles of various length; hind coxa with one long black outer bristle above middle; fore femur with numerous dark fine erect ventral hairs, at most half as long as diameter of femur, and 3 long black posteroventral cilia; fore tibia simple, with elongate ventral and posterior setulae, 1 anterodorsal and 1 posterodorsal at base, 1-2 dorsals in middle, 1-2 apical setae; basitarsus with elongate setulae ventrally, slightly thickened at apex; $2^{\text {nd }}$ to $5^{\text {th }}$ segments with full posteroventral row of strong erect setulae; $2^{\text {nd }}$ to $4^{\text {th }}$ segments with 1-2 short dorsoapical setae; claws simple; mid femur with strong anterior preapical seta, with erect black ventral hairs, at most half as long as diameter of femur; mid tibia with 3 anterior, 3 posterodorsal, 3-5 ventral, 4-5 apical setae; mid basitarsus with several short ventral setae; hind femur without long hairs, with 1 strong anterior preapical seta; hind tibia with 3-4 anterior, 2 anterodorsal, 2 posterodorsal, 3-4 apical setae. Femur, tibia and tarsomere (from first to fifth) length ratio: fore leg: 17/20/13/10/5/8/3, mid leg: 18/24/15/6/5/3/2, hind leg: $16 / 26 / 7 / 8 / 4 / 3 / 2$.

Wing greyish, veins brown; subcosta very thin; ratio of part of costa between $\mathrm{R}_{2+3}$ and $\mathrm{R}_{4+5}$ to that between $\mathrm{R}_{4+5}$ and $\mathrm{M}_{1}, 5 / 1 ; \mathrm{M}_{1}$ with gentle arc to apex, reaching costa right before wing apex; $\mathrm{M}_{2}$ present as fold on membrane; crossvein $d m-m$ straight; ratio of crossvein $d m-m$ to apical part of $\mathrm{M}_{1+2}$ (fork-handle) to apical part of $\mathrm{M}_{4}, 5 / 15 / 15$; anal vein foldlike, not reaching wing margin; anal angle obtuse; lower calypter yellow, with black apex and pale setae; halter yellow with orange knob, halter stem thin and long, with dorsal and ventral groups of short hairs distally.

Abdomen mostly yellow-orange, black setose; $1^{\text {st }}$ segment yellow, with small brown posterior spot dorsally; $2^{\text {nd }}-5^{\text {th }}$ yellow, with black edgings anteriorly and posteriorly; the edgings wider dorsally; $6^{\text {th }}, 8^{\text {th }}$ segments and epandrium entirely black; epandrial lobes brown; hypandrium small, simple; phallus thin and simple; 1 reduced epandrial lobe bearing 2 long apical setae at base of hypandrium; 1 long epandrial lobe distally bearing small ventral subapical spine; 1 longer distoventral lobe bearing 1 long and 1 short subapical setae and small declinate apical lobule with 
fringe of 8 setulae at apex; 1 very long and broad sword-shaped striated distoventral lobe, as long as epandrium, bearing small apical spine; surstylus black, long and curved, half as long as epandrium, bearing 1 minute seta on angular apex, 3 short setae at middle and trangular dorsal tooth at middle; cercus yellow, twice longer than epandrium, elongate-rectangular, with toothed distal margin, covered with long, mostly black hairs, denser at apex.

MEASUREMENTS (in mm). Body length 6.0; antenna length 1.5; wing length 6.2; wing width 1.9 , hypopygium 1.4 .

DISTRIBUTION.Type locality: Kenya. DR Congo, Kenya.

DIAGNOSIS. T. unicolor belongs to a group of species with uniseriate acrostichals, being the closest to $T$. shcherbakovi, differing from the latter in male and female postpedicel oval, longer than high; male cercus band-like, almost evenly wide (see key above).

NOTES. The species was described by a single female taken by the expedition of Ch. Alluaud and R. Jeannel from environs of Mt. Kenya at $2400 \mathrm{~m}$ a.s.l. as follows from the original paper of Becker (1914) and from the date of collection (22 January 1912). It was later recorded by females only (Grichanov, 1996, 2000). The holotype must be deposited in the collection of Muséum National d'Histoire Naturelle (Paris, France), but it was not found there, as well as in other European museums keeping Becker's types, being most probably lost. Therefore, I designate here the neotype of Psilopus unicolor collected not far from the type locality. The specimen corresponds to the original description by Becker $(1914,1923)$ and to the diagnosis of Tenuopus unicolor female provided by Grichanov (1996).

\section{CONCLUSION}

As a result of our study, a new subfamily Tenuopodinae Grichanov, subfam. $\mathbf{n}$. is created for the genus Tenuopus Curran, 1924, sharing some features of Neurigoninae, Peloropeodinae and Sciapodinae. Six new species are described from the continental Afrotropics. Descriptions of males of two species known previously by females are also given. A revised key to 19 known Tenuopus species is provided.

Many species of the genus seem to be extremely rare in nature, often known by a few specimens or/and from the type locality only. Tenuopus acrosticalis is the most widespread species. In general, species of the genus are known from Burundi, Central African Republic, Republic of the Congo, DR Congo, Ghana, Ivory Coast, Kenya, Liberia, Malawi, Mozambique, Nigeria, Sierra Leone, South Africa, Tanzania and Uganda, usually from local mountainous regions. The habitus of Tenuopus species is quite similar to that in some yellow-coloured species of Amblypsilopus Bigot, 1888 and Neurigona Rondani, 1856. Therefore, I consider a record (Dyte, 1975) of an undescribed Tenuopus species from the Oriental Region as doubtful.

\section{ACKNOWLEDGEMENTS}

I am greatly indebted to Drs. Ashley H. Kirk-Spriggs (BMSA), Mike Mostovski (NMSA), Thomas Pape (ZMUC), Roy Danielsson (MZLU), N.E. Vikhrev and A.L. 
Ozerov (ZMUM) for their kindness in furnishing an opportunity to study the collections of their Museums. Two anonymous reviewers kindly commented on earlier drafts of the manuscript.

\section{REFERENCES}

Becker, T. 1914. Diptères nouveaux récoltés par MM. Ch. Alluaud et R. Jeannel en Afrique orientale 1911-1912. Annales de la Société Entomologique de France, 83: 120-130.

Becker, T. 1923. Dipterologische Studien. Dolichopodidae. D. Aethiopische Region. Entomologische Mitteilungen, 12: 1-50.

Bickel, D.J. 1994. The Australian Sciapodinae (Diptera: Dolichopodidae), with a review of the Oriental and Australasian faunas, and a world conspectus of the subfamily. Records of the Australian Museum, Supplement 21: 1-394.

Bickel, D.J. 1998. The Dolichopodidae (Diptera) of Midway Atoll, with a new species of Dactylomyia Aldrich, and taxonomic notes on the subfamily Neurigoninae. Bishop Museum Occasional Papers, 55: 45-55.

Bickel, D.J. 2009. Chapter 49. Dolichopodidae (long-legged flies). P. 671-694. In: Brown, B.V., Borkent, A., Cumming, J.M., Wood, D.M., Woodley, N.E. \& Zumbado, M.A. (Eds.). Manual of Central American Diptera, Volume 1. NRC Research Press, Ottawa.

Cumming, J.M. \& Wood, D.M. 2017. 3. Adult morphology and terminology. P. 89-134. In: Kirk-Spriggs, A.H. \& Sinclair, B.J. (Eds.). Manual of Afrotropical Diptera. Volume 1. Introductory chapters and keys to Diptera families. Suricata 4. SANBI Graphics \& Editing, Pretoria

Curran, C.H. 1924. The Dolichopodidae of South Africa. Annals of the Transvaal Museum, 10: $212-232$.

Curran, C.H. 1927a. New Dolichopodidae from the Ethiopian Region. Annals and Magazine of Natural History, 9(19): 1-16.

Curran, C.H. 1927b. Records and description of Ethiopian Dolichopodidae. Revue de Zoologie Africaine, 15(2): 241-266.

Dyte, C.E. 1975. Family Dolichopodidae. P. 212-258. In: Delfinado, M.D. \& Hardy, D.E. (Eds.). A Catalog of the Diptera of the Oriental Region, II. University of Hawaii Press, Honolulu.

Dyte, C.E. \& Smith, K.G.V. 1980. Family Dolichopodidae. P. 443-463. In: Crosskey, R.W. (Ed.). Catalogue of the Diptera of the Afrotropical Region. British Museum (Natural History), London.

Grichanov, I.Ya. 1996. Afrotropical species of the genus Tenuopus Curran (Diptera: Dolichopodidae). An International Journal of Dipterological Research, 7(2): 125-131.

Grichanov, I.Ya. 2000. Afrotropical Neurigoninae and notes on the diaphorine genus Dactylonotus Parent (Diptera: Dolichopodidae). Belgian Journal of Entomology, 2: 257271

Grichanov, I.Ya. 2011. An illustrated synopsis and keys to Afrotropical genera of the epifamily Dolichopodoidae (Diptera: Empidoidea). Priamus Serial Publication of the Centre for Entomological Studies Ankara, Supplement 24: 1-99.

Grichanov, I.Ya. 2018. An annotated catalogue of Afrotropical Dolichopodoidae (Diptera). VIZR, St.Petersburg. 152 pp. (Plant Protection News Supplements, 25).

Grichanov, I.Ya. \& Brooks, S.E. 2017. 56. Dolichopodidae (long-legged dance flies). P. 1265-1320. In: Kirk-Spriggs, A.H. \& Sinclair, B.J. (Eds.). Manual of Afrotropical Diptera, Volume 2. Nematocerous Diptera and Lower Brachycera. Suricata 5. SANBI Graphics \& Editing, Pretoria. 
Grichanov, I.Ya., Mostovski, M.B. \& Muller, B. 2011a. New records of Afrotropical Dolichopodidae (Diptera) from the collection of Natal Museum (1). An International Journal of Dipterological Research, 22(1): 3-9.

Grichanov, I.Ya., Mostovski, M.B. \& Muller, B. 2011b. New records of Afrotropical Dolichopodidae (Diptera) from the collection of Natal Museum (2). An International Journal of Dipterological Research, 22(2): 81-98.

Naglis, S. 2001. Revision of the Neotropical Neurigoninae (Diptera: Dolichopodidae) I: Coeloglutus Aldrich, Neotonnoiria Robinson, and Paracoeloglutus gen. nov., with the definition of the tribe Coeloglutini stat. nov. Studia dipterologica, 8(1): 189-206.

Parent, O. 1931. Quelques Dolichopodides nouveaux conservés au British Museum. Annales de la Société Scientifique de Bruxelles, B, Mémoirs, 51: 39-47.

Parent, O. 1934. Additions à la faune ethiopienne. Bulletin de la Société Royale Entomologique d'Egypte, n.s., 18: 112-138.

Parent, O. 1938. Diptères Dolichopodidae. Faune de France, Paris, 35.720 pp.

Parent, O. 1939. Diptères Dolichopodides de la region ethiopienne. Revue de Zoologie et Botanique Africaine, 32: 256-282.

Yang, D., Zhu, Y.J., Wang, M.Q. \& Zhang, L.L. 2006. World catalog of Dolichopodidae (Insecta: Diptera). China Agricultural University Press, Beijing. 704 pp. 